\title{
Electromagnetic Shielding Effectiveness of Historic Buildings: The Heritage Stone Town of Zanzibar
}

\author{
Khalfan Amour Khalfan, Richard M. Besha and Dennis N. G. A. K. Tesha \\ School of Architecture, Construction Economics \& Management, Ardhi University, Dar Es Salaam, Tanzania
}

\begin{abstract}
Owing to health and security hazards posed by concentration of EMR (electromagnetic radiations) from wireless transmission devices such as antennas and WiFi, it is time for building specialists to consider EMR shielding in general designs. Such a venture needs understanding of shielding behavior of various building materials in their isolated and combined forms. While shielding properties of several industrial materials are known, much remains to be understood from traditional materials. This article contributes to the knowledge of SE (shielding effectiveness) of the latter materials. It has tested the buildings of the 19th CE STZ (Stone Town of Zanzibar). The coral stones, mud, and mangrove pole buildings of this historic town were found to be effective in shielding the radiations, nearly the same as renowned buildings of the Roman Empire.
\end{abstract}

Key words: Buildings, electromagnetic radiations, environmental shielding, Zanzibar Stone Town.

\section{Introduction}

EMR (Electromagnetic radiations) present both opportunities and threats. Today's wireless telecommunication would have been impossible without it. However, they are pronounced as potentially hazardous to human health, animals and plants. Among the said detriments of EMR exposure to human include cancer, discomfort stress, and sexual impotency [1]. In India, EMR from mobile telecom antennas are linked to a huge loss of honeybees because the radiations interfere with bees' navigation system, which is magnetic in nature [2]. With the introduction of WiFi at homes and offices today, whose waves are more powerful, a much greater risk to health and live hood is posed [3]. Nonetheless, there are reports that deny a correlation between EMR and health hazards [4, 5], thus, creating opposing views on the issue. This difference in opinions makes the study of EMR and its effects controversial. A literature review of studies supporting presence of the effects and

Corresponding author: Khalfan Amour Khalfan, Ph.D., lecturer; research fields: architectural conservation, and historic building heritage. E-mail: khalfan@aru.ac.tz, khalfanani@gmail.com. those opposing indicate strong points on both sides. In any case, effects of EMR may not be seen in a shorter term. There is a general saying that, everything in this world has benefits and disbenefits. The matter of fact is whether the benefits outweigh the detriments. Therefore, it is convincing to believe in the EMR negative effects, or at least their potential existence. In doing so, we will be prepared for the effects.

Owing to the potential of EMR health hazards, research on how we can make living environment safer from the radiations is very important. Ogrutan et al. [6] support this idea. They further foresee its benefits to designing intelligent buildings, control over equipment interference, and prohibition of electronic spying. A look at previous researches revealed some activities on building materials. Lasiter [7] is probably among the first to measure attenuation of concrete, i.e. how much of energy radiation is absorbed by the material. Lee and Yen [3] studied the capacity of cement mortar to absorb EMR emitted by appliances in a confined living space. On the other hand, Cho et al. [8] researched on EMR shielding effect of "eco-friendly foamed concrete wall". These studies intended to enhance penetration of EMR contrary to the present study that advocates shielding 
but, their results also indicate the material's defense ability against EMR. Ahmadi-Shokouh [9] looked into properties of some floor finishes to the radiations. In their research, Micheli et al. [10] examined the EMR attenuation of historic buildings of the Roman Empire with concrete composite walls. Again, they focused on the shielding property of the walls, as to why they prevent use of electronic devices, similar to others.

Three aspects inspired the present article on EMR shielding. First is shielding property of historic buildings, which is under researched. Second is the fact that, most researches concentrated on metallic materials and modern building materials, concrete, aluminum sheets and glass in particular. Attenuation of traditional materials is hardly understood. The third is the environmental benefits of attenuation. Buildings are constructed to protect their occupants from undesirable external agents. Up to the present time, architects and building specialists mostly regard rain, heat, wind and light as key elements of environmental design in buildings [11]. EMR shielding in general building designs is uncommon [12]. At any rate, with increasing intensity of EMR environment, it might become necessary to control radiations' entering our buildings. Consequently, this article suggests consideration of EMR environment as another important dimension of environmental building design. To achieve envisaged control, SE (shielding effectiveness) of various building materials, both in composite and in isolation need to be understood. This article is interested with SE of traditional building materials of the heritage STZ (Stone Town of Zanzibar), Tanzania. Major building materials of the town structures are coral stones and lime-soil mortar, typical of historic buildings of East African Coast. The findings of this article would help building designers in controlling electromagnetic environment.

\section{Methodology}

Several procedures exist to measure SE. In this research, SE of the walls was determined according to
IEEE [13]. A survey was initially carried out to map EMR environment and frequency bands around the town. The town is the urban center of Zanzibar Islands and a tourism destination. Therefore, there is a huge concentration of transmission antennas from five (5) mobile operators, namely Vodacom, Tigo, Zantel, Airtel and Halotel. Zantel is the oldest provider with the widest coverage. She has positioned not only transmission towers but also low-level antennas to boost coverage as radio waves find it difficult to penetrate the town's stone buildings especially on ground floor. Zantel transmits the waves in $2 \mathrm{G}$ (frequency $900 \mathrm{MHz}-1,800 \mathrm{MHz}$ ), 3G (frequency $2,100 \mathrm{MHz}$ ), and $4 \mathrm{G}$ (frequency $800 \mathrm{MHz}$ ) environments. This provider and the frequency bands were used in the measurement of SE. There are also WiFi transmissions in the area. However, WiFi bands are less controlled as the local transmitters can choose to put them on or off anytime, hence they were excluded in the measurements.

Measuring instruments involved were simply smart phones. To minimize instrumental errors, two (2) phones of the same brand, Samsung Galaxy A8 were used. This phone brand is among the strongest in catching up with the network. SIM cards were fitted in the phones and G-Net Track Lite v6.2 software was installed in the phones. The software can display transmitters' ID, type, frequency in terms of generation whether $2 \mathrm{G}, 3 \mathrm{G}$, or $4 \mathrm{G}$, signal strength and their intensity with time. It can also print data reports from the measurements. One phone was placed outside the external wall (enclosure) to read the outdoor received frequency values and another inside the wall at $300 \mathrm{~mm}$ to record the indoor values (Fig. 1). Measurements were performed to buildings randomly selected at different areas of the town. Results of the measurements are presented in Table 1. The SE was computed by taking the difference between the outdoor and the indoor values as follows:

where,

$$
S E(\mathrm{~dB})=E_{1}-E_{2} \quad([13], \text { p. 31 })
$$




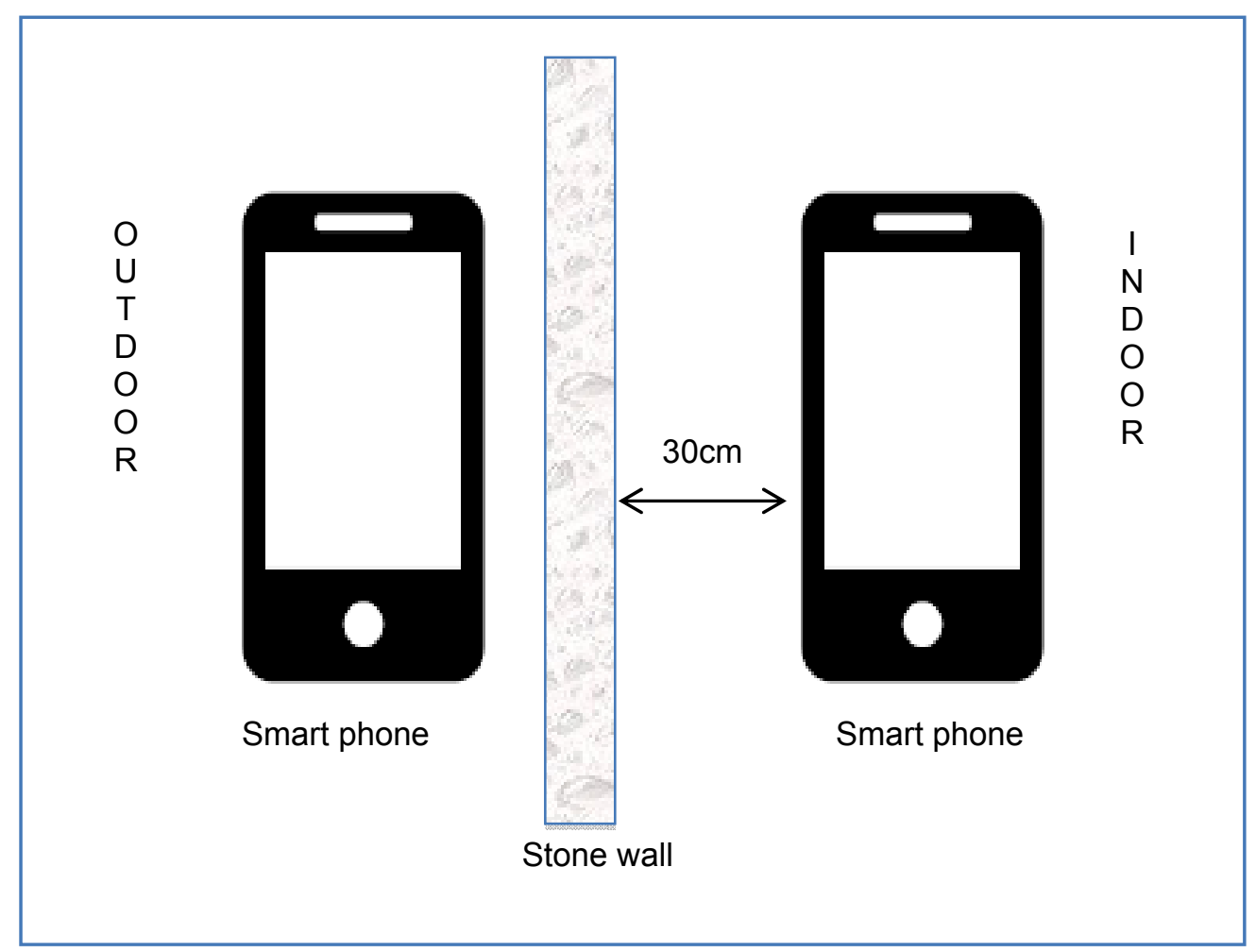

Fig. 1 Set up for measurement of SE.

$E_{1}$ is the frequency in the absence of the enclosure;

$E_{2}$ is the frequency within the enclosure.

Results of the SE were analyzed and discussed in the Results and Discussion section of this article.

\section{Buildings of the Historic Stone Town of Zanzibar}

The STZ started as a fishing village and developed into a mercantile metropolis of East Africa in the 19th century [14]. Its oldest surviving traditional stone and mud building dates back to 1830. Arab and Indian merchants constructed 2-3 storey buildings with coral stone walls bonded in mud and lime mortar. The stones' configuration within the walls was largely rubble. The buildings' floors were also from the same materials but supported by mangrove poles at $30 \mathrm{~cm}$ centers (Fig. 2a). This construction resulted into massive load bearing structures with oblong windows punching external walls (Fig. 2b).

Builders opted for large story heights to allow breeze easily penetrate the interior from surrounding narrow, organic streets (Fig. 2c). For strength and stability reasons, the buildings have massive walls at ground and at least first floors. Although the Arab and Indian buildings share the same material and construction techniques, they differ significantly in typology. Arab buildings are huge rectangular mansions with open yards at the center. The Indian's on the other hand are smaller and narrow, typically constructed as adjoining row houses.

The combination of the buildings' design and the town's plan of narrow, organic and winding streets appear to have dramatic effect on the penetration of EMR into the buildings. Residents' complaints of weak mobile phone signal reception are indications of restricted penetration. This has made some cellular phone providers to install additional low-level antennas to boost transmission and penetration. However, in Arab structures, courtyards receive better signals than Indians' packed row houses and residents in Arab buildings are used to keeping their mobile phones around courtyard areas. This stimulates the need to study 
Table 1 Records of indoor, outdoor readings and computation of SE.

\begin{tabular}{|c|c|c|c|c|c|c|c|}
\hline Stone Town area & House No. & $\begin{array}{l}\text { Wall thickness } \\
(\mathrm{cm})\end{array}$ & Signal type & Receiving cell ID & $\begin{array}{l}\text { External } \\
\text { reading }(\mathrm{dBm})\end{array}$ & $\begin{array}{l}\text { Internal reading } \\
(\mathrm{dBm})\end{array}$ & $\begin{array}{l}\mathrm{SE} \\
(\mathrm{dBm})\end{array}$ \\
\hline Shangani & 77 & 60 & $4 \mathrm{G}$ & 30842 & 89 & 91 & 2 \\
\hline Vuga & 323 & 60 & $4 \mathrm{G}$ & 30883 & 93 & 95 & 2 \\
\hline Darajani & B1-73 & 60 & $4 \mathrm{G}$ & 25593 & 93 & 95 & 2 \\
\hline Malindi & 1206 & 65 & $2 \mathrm{G}$ & 34006 & 95 & 99 & 4 \\
\hline Darajani & 265 & 70 & $2 \mathrm{G}$ & 25596 & 83 & 89 & 6 \\
\hline Kiponda & 1250 & 62 & $3 \mathrm{G}$ & 34006 & 83 & 91 & 8 \\
\hline Malindi & 154 & 70 & $4 \mathrm{G}$ & 20861 & 79 & 87 & 8 \\
\hline Vuga & 500 & 60 & $2 \mathrm{G}$ & 20881 & 95 & 103 & 8 \\
\hline Mkunazini & 697 & 60 & $3 \mathrm{G}$ & 14003 & 95 & 105 & 10 \\
\hline Hamamni & Bath & 62 & $3 \mathrm{G}$ & 20861 & 79 & 91 & 12 \\
\hline Hurumzi & Marumaru & 60 & $3 \mathrm{G}$ & 30863 & 85 & 97 & 12 \\
\hline Forodhani & Old Fort & 120 & $4 \mathrm{G}$ & 50863 & 65 & 79 & 14 \\
\hline Malindi & 912 & 75 & $3 \mathrm{G}$ & 14003 & 77 & 91 & 14 \\
\hline Mkunazini & 487 Masjid & 60 & $3 \mathrm{G}$ & 50865 & 81 & 97 & 16 \\
\hline Kajificheni & 465 & 60 & $4 \mathrm{G}$ & 30862 & 79 & 95 & 16 \\
\hline Forodhani & Old Fort & 80 & $3 \mathrm{G}$ & 50866 & 75 & 91 & 16 \\
\hline Hurumzi & 711 & 75 & $2 \mathrm{G}$ & 14003 & 89 & 105 & 16 \\
\hline Hurumzi & 631 & 65 & $3 \mathrm{G}$ & 14003 & 89 & 105 & 16 \\
\hline Darajani & 1195 & 70 & $3 G$ & 14003 & 87 & 103 & 16 \\
\hline Shangani & 544 & 90 & $3 \mathrm{G}$ & 10843 & 57 & 75 & 18 \\
\hline Vuga & 327 & 70 & $3 G$ & 30844 & 85 & 103 & 18 \\
\hline Darajani & 1200 & 65 & $3 \mathrm{G}$ & 14003 & 87 & 105 & 18 \\
\hline Forodhani & PBZ & 60 & $3 \mathrm{G}$ & 30863 & 81 & 101 & 20 \\
\hline Hamamni & 1950 & 135 & $2 \mathrm{G}$ & 30861 & 85 & 105 & 20 \\
\hline Malindi & 1966 & 55 & $3 G$ & 30861 & 83 & 103 & 20 \\
\hline Vuga & 2199 & 75 & $3 \mathrm{G}$ & 30861 & 87 & 107 & 20 \\
\hline Malindi & 656 & 60 & $3 \mathrm{G}$ & 34006 & 85 & 105 & 20 \\
\hline Mkunazini & 293 & 75 & $3 \mathrm{G}$ & 30836 & 71 & 91 & 20 \\
\hline Darajani & 980 & 70 & $3 \mathrm{G}$ & 14003 & 81 & 101 & 20 \\
\hline Kajificheni & $95 \mathrm{~A}$ & 75 & $3 G$ & 30862 & 83 & 105 & 22 \\
\hline Shangani & 155 & 46 & $2 \mathrm{G}$ & 30863 & 83 & 105 & 22 \\
\hline Shangani & Masjid & 60 & $3 \mathrm{G}$ & 30843 & 71 & 93 & 22 \\
\hline Malindi & 216 & 55 & $3 \mathrm{G}$ & 30861 & 89 & 111 & 22 \\
\hline Vuga & 501 & 70 & $3 \mathrm{G}$ & 30863 & 91 & 113 & 22 \\
\hline Mkunazini & 622 & 75 & $3 \mathrm{G}$ & 14003 & 91 & 113 & 22 \\
\hline Hurumzi & 292 & 65 & $3 \mathrm{G}$ & 30832 & 79 & 101 & 22 \\
\hline Malindi & 662 & 70 & $2 \mathrm{G}$ & 34006 & 79 & 103 & 24 \\
\hline Mkunazini & 712 & 60 & $3 G$ & 30831 & 87 & 111 & 24 \\
\hline Darajani & 685 & 60 & $3 \mathrm{G}$ & 14003 & 67 & 91 & 24 \\
\hline Shangani & 158 & 65 & $3 G$ & 30863 & 81 & 107 & 26 \\
\hline Malindi & 391 & 60 & $2 \mathrm{G}$ & 30863 & 81 & 107 & 26 \\
\hline Vuga & 496 & 70 & $3 \mathrm{G}$ & 30844 & 81 & 107 & 26 \\
\hline Hamamni & 1999 & 65 & $2 \mathrm{G}$ & 20862 & 57 & 85 & 28 \\
\hline Kajificheni & School & 69 & $3 \mathrm{G}$ & 30862 & 51 & 79 & 28 \\
\hline Hamamni & 1999 & 65 & $3 G$ & 20862 & 75 & 105 & 30 \\
\hline Hurumzi & 194 & 57 & $3 G$ & 30863 & 79 & 109 & 30 \\
\hline Hamamni & 1762 & 65 & $3 \mathrm{G}$ & 20861 & 79 & 111 & 32 \\
\hline Kiponda & 1275 & 60 & $3 \mathrm{G}$ & 34006 & 79 & 111 & 32 \\
\hline Mkunazini & 760 & 70 & $3 \mathrm{G}$ & 30835 & 63 & 103 & 40 \\
\hline
\end{tabular}




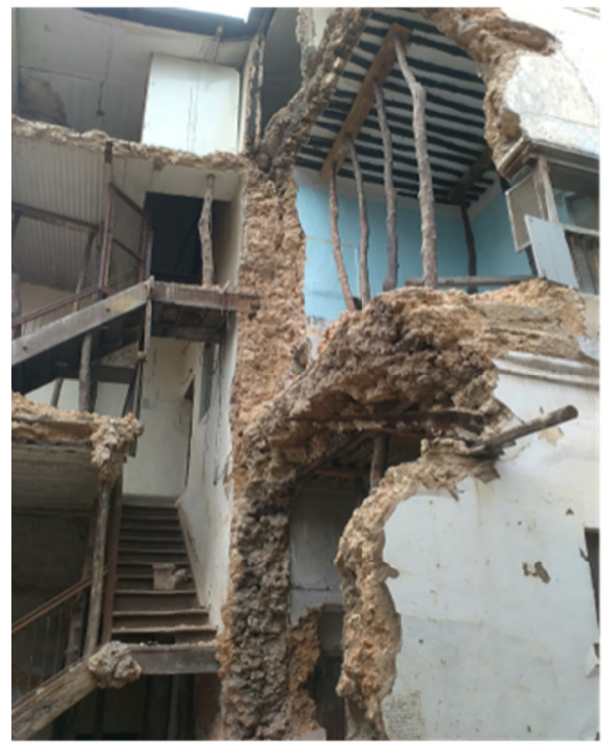

(a)

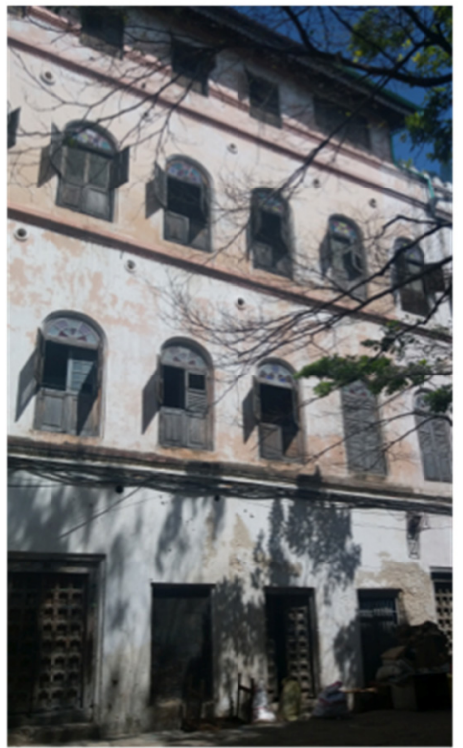

(b)

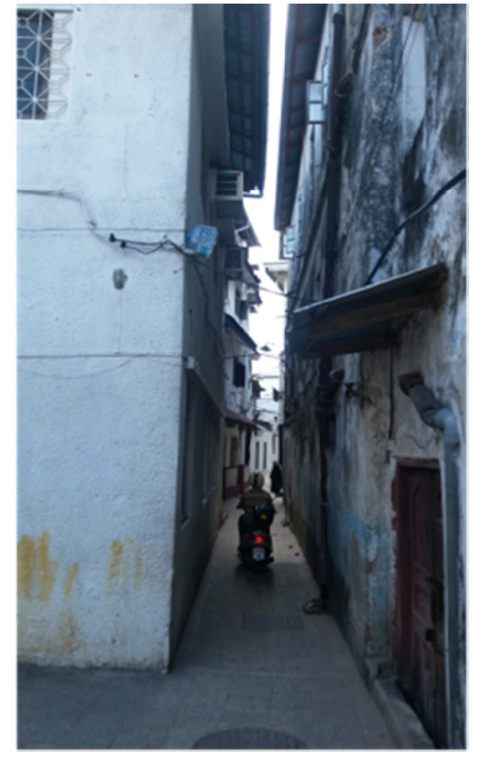

(c)

Fig. 2 (a) Partially collapsed building revealing its massive walls and mangrove supported floors; (b) oblong windows on external wall; and (c) a narrow street measuring $1.6 \mathrm{~m}$ wide.

EMR penetration both outdoors to indoor and indoor transmission in the different building types. The massive walls in particular, are worth an in depth study on the way stonewalls prevent penetration of EMR.

\section{Analysis and Discussion}

At the outset, pilot measurements were conducted to check reliability of the instruments used. Signals are assigned 5-digit numbers by service transmitters known as cell ID's. There were several transmitting cells from a single antenna. Using the ID's, one can track indoor signal coming from outdoor. To further check the signal identity, the cell ID digits were confirmed to Zantel and found to correspond with the range of $2 \mathrm{G}, 3 \mathrm{G}$ and $4 \mathrm{G}$ frequency bands assigned to this company and recorded by the phones.

In this research, measurements of SE were performed in 49 buildings. Some of these buildings include monuments constructed of very thick walls up to $135 \mathrm{~cm}$. But, most walls measured $60 \mathrm{~cm}$ thick in majority of residential structures. The walls' mass constitutes rubble stones bonded with lime-soil mortar. Thickness of bonding mortar is not uniform in this traditional construction and varies between walls of different buildings. Internal and external plasters are made from the same mortar and their thickness range between $50-75 \mathrm{~mm}$. The plaster is applied in two layers; one inner layer called "mtomo" is a combination of mortar and pebbles, followed by the top layer of mortar only (Fig. 3). Therefore, it was difficult to determine accurately the impact of the plaster in the walls' SE and so the SE reported in this case is taken as composite for the whole wall. Originally, lime wash was used to paint the buildings. Nowadays some apply water based modern paints but can be considered to have negligible effect in the overall attenuation of EMR compared to those with lime wash.

The strongest signal recorded outside the buildings was $-51 \mathrm{dBm}$ with an indoor value of $-79 \mathrm{dBm}$ for a 90 $\mathrm{cm}$ thick wall. This gives an attenuation of $28 \mathrm{dBm}$. According to the transmitter (Zantel), attenuation values $<15 \mathrm{dBm}$ allow a good penetration of the EMR and users can make and receive phone calls relatively well. For attenuation $\geq 20 \mathrm{~dB}$, greater shielding of EMR results and users can hardly operate their phones [10]. With regards to outdoor values, a signal of $-75 \mathrm{~dB}$ $\pm 15 \mathrm{~dB}$ (i.e. $-60 \mathrm{~dB}$ to $-85 \mathrm{~dB}$ ) is considered adequate for potential indoor penetration regardless of the obstacle. The values recorded during field measurements presented in Fig. 4 a indicate largely good strength of 


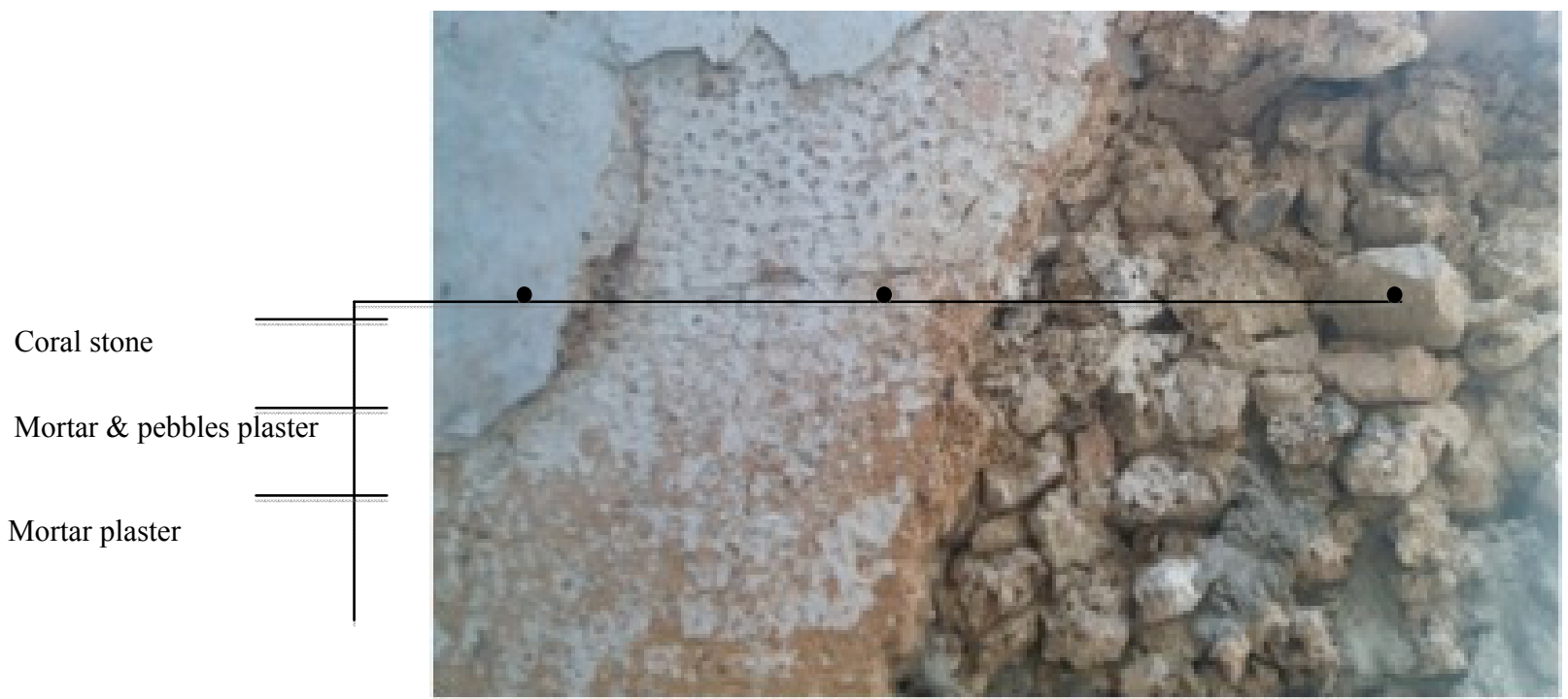

Fig. 3 A wall displaying the structural stones and layers of plasterwork.

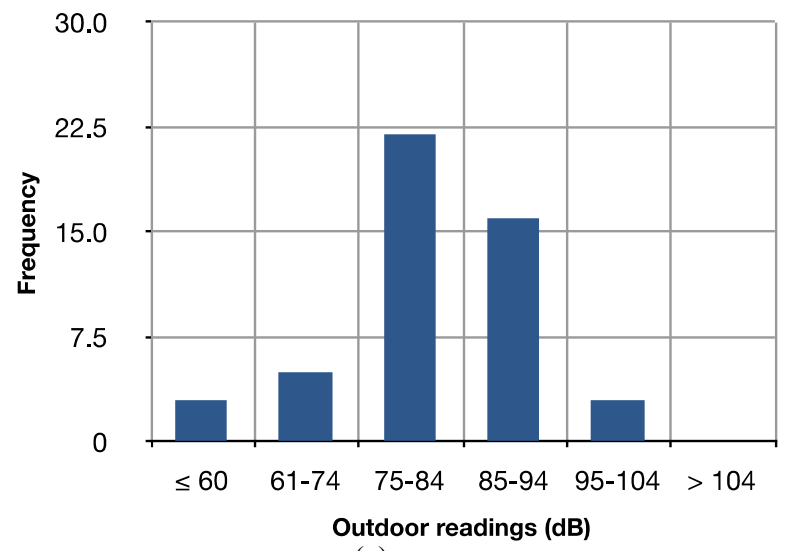

(a)

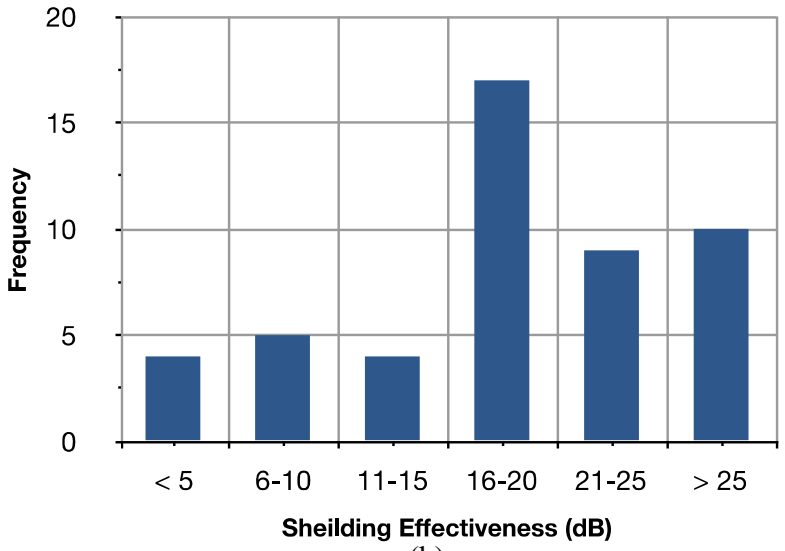

(b)

Fig. 4 (a) Outdoor signal measurements and (b) computed SE from outdoor and indoor values.

outdoor signals $(\leq 60-84 \mathrm{~dB})$. However, a significant part of it can be regarded as relatively weak (85-104 $\mathrm{dB})$.

Outdoor signal weakness may be attributed to the denseness of the STZ fabric. The town's plan developed in an organic way. There is no conceived formal plan for space between houses, no for the streets and their directions. The paths are generally narrow and winding, allowing only pedestrians, carts, and motorbike to move around. A typical narrow street is about 1.5-2 meters wide. There is even less than a meter street, known as "suicide street" (Fig. 5a). Further, the buildings have thick walls as shown in
Table 1. This situation restricts both outdoor transmissions between streets and building blocks and indoor penetrations. Notwithstanding buildings' SE under this study, the shielding effect of the STZ environment is therefore of interest and could be taken as area for further study.

Field measurements generally showed no strong correlation between wall thickness and SE as portrayed in Fig. 5b, though the shielding capacity of the individual walls is high. For exceptionally very thick walls, of 90, 120 and $135 \mathrm{~mm}$ thick observed, the SE was recorded as 18,14 and $20 \mathrm{~dB}$ respectively, while in average a $60 \mathrm{~mm}$ thick wall showed an SE of $20 \mathrm{~dB}$ and 


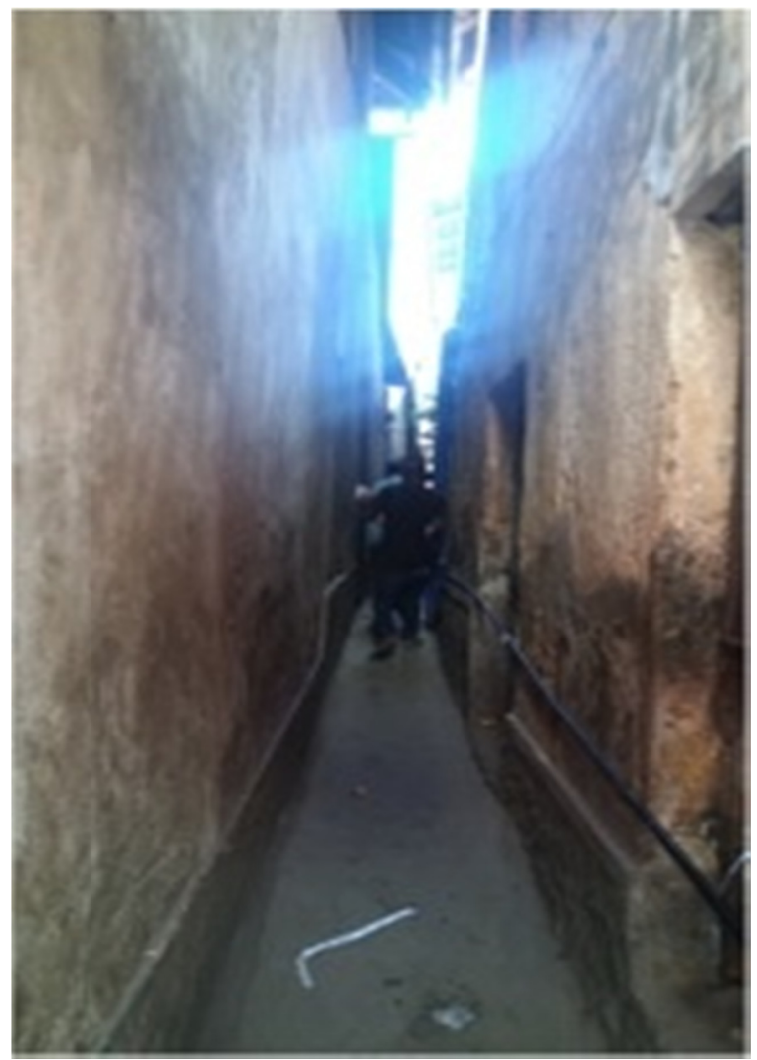

(a)

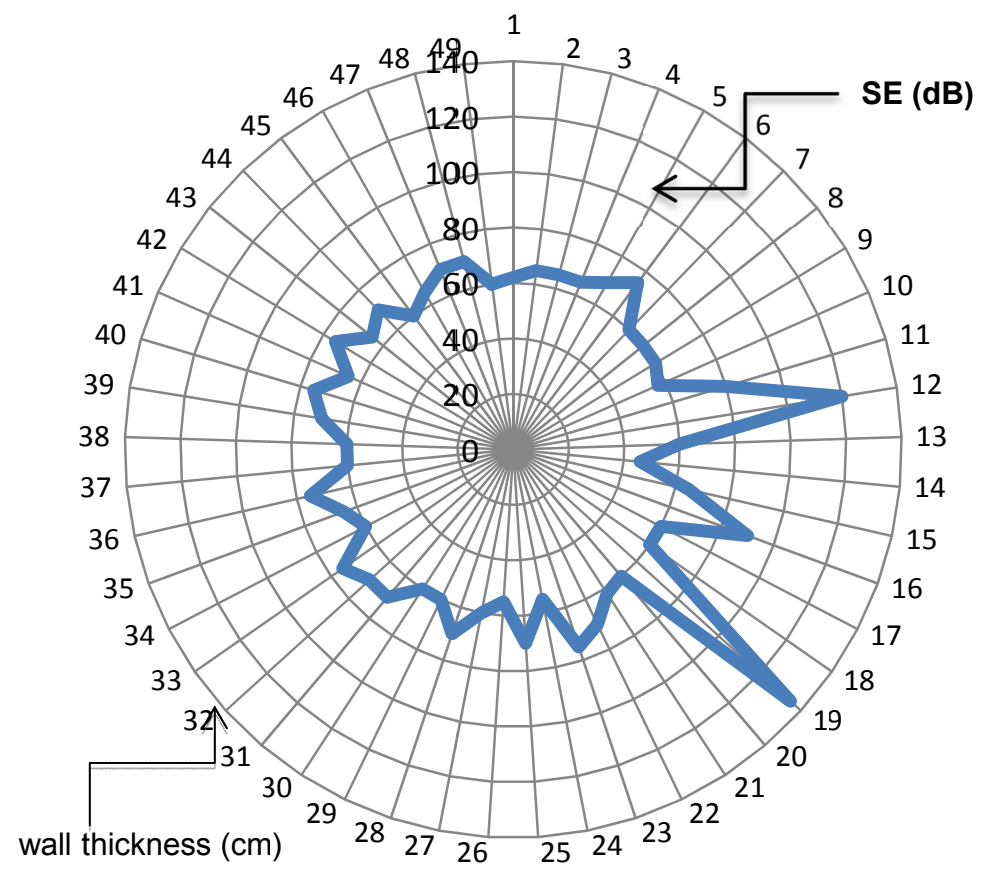

(b)

Fig. 5 (a) "Suicide street" at Darajani market area allows only one person to pass at a time and (b) scatter diagram of wall thickness and their SE. 
above with exception of few walls. Thick stonewalls of this town appear to be more porous than thinner walls. This is because to construct thick walls requires more stones and additional bonded mortar joints therefore, the probability that amount of voids in the overall wall mass is high. However, this is not only for thick walls, the use of coral stones in the construction of buildings in STZ has generally introduced voids and so reduced the ability of the walls to restrict electromagnetic waves. If completely solid stones were used, their effectiveness against the radiations would have improved.

From Table 1, the highest value of SE recorded was $40 \mathrm{dBm}$ while the lowest was $2 \mathrm{dBm}$. Although there is a wide discrepancy between the walls' SE, about $73 \%$ of the walls significantly attenuated EMR to a restrictive level of mobile phone penetration mentioned by the above transmitter, and this affirms the complaints for restricted phone use by STZ residents. Therefore, the buildings of the historic STZ are potential to shield its occupants from EMR. The construction technology and materials of these buildings worth attention of building designers.

In general, walls of $60-70 \mathrm{~cm}$ thick provide adequate barrier to EMR of at least $20 \mathrm{~dB}$. The highest shielding of $40 \mathrm{~dB}$ was recorded for a $70 \mathrm{~cm}$ wall. However, walls thinner than $60 \mathrm{~cm}$ performed better in some occasions. Again, this difference could be due to masons' construction skills, types of stones used, stones' configuration, and thickness of lime mortar employed. Moisture content within the wall mass could also affect the SE nonetheless, this could not be ascertained.

SE of objects cannot be attributed to their geometry (i.e. size, shape, volume, weight, etc.) alone, it has to be looked upon the type of signal falling on them. Signal types relate to their strength of transmission. EMR are transmitted at different wavelengths each of which defines their embedded energy. A correlation between $\mathrm{SE}$ and signal type was observed in this research. $4 \mathrm{G}$ waves have high frequency so they penetrated more into the walls than low frequency waves such as $3 \mathrm{G}$. In such a case the walls recorded lower SE. The lower SE at high frequency confirms the presence of voids in the stonewalls as pointed out by Micheli et al. [10] who noted the same when determined SE of ancient Roman buildings of 700 and $1500 \mathrm{CE}$. In addition to the voids there are possibly cracks formation within the STZ building walls that weakens the walls' ability to shielding. The buildings of the historic town take too long to be repaired. A survey in 1992 established that only $14 \%$ of the town's buildings are in good condition, the rest are either deteriorating, poor, in ruins or have collapsed [14]. The situation has not changed much over the past years. Different attenuation of various signals can be taken as another check for reliability of instruments used to collect the data reported in Table 1.

Data collected in this research were compared to similar studies to understand the relative strength of the STZ buildings' walls in attenuating EMR. Some of these studies tested SE of building materials in their original form, others in modified form. One comparable study was that of Micheli et al. [10] who examined attenuation of buildings in Rome. He measured historic buildings of the Roman Empire (700-1500 CE) and found to have SE range of 25-35 $\mathrm{dB}$. The historic buildings of the STZ compare pretty well to the Roman buildings with average SE range 20-32 dB. However, the former were constructed with bricks and concrete while the latter employ stone and lime-soil mortar. Bricks and concrete is a regular construction and the amount of pore spaces can be controlled more than in the stone structures. That is to say, the SE of STZ buildings is significant even under unregulated construction circumstances.

\section{Conclusion}

This research joins hands to advocate the control of electromagnetic radiations entering our buildings. It has tested the efficiency of historic buildings from the heritage Stone Town of Zanzibar to shield from 
electromagnetic radiations. The research was motivated by the fact that measurement of shielding effectiveness has concentrated much on modern materials and so forgot the role that traditional materials such as stone and mud can play in this task. The town's buildings were found to have considerable shielding from the radiations nearly the same as that of famous Roman Empire of the 700-1500 CE. Although the highest value of shielding recorded was $40 \mathrm{~dB}$, in average the walls achieved a threshold of $22 \mathrm{~dB}$ adequate to restrict operation of wireless telecommunication devices. This indicates that, historic towns are not only eco-friendly and sustainable from their material point of view but also they are potential protectors of hazardous radiations.

Researches on electromagnetic radiation shielding of buildings and their materials have been of great interest to electronics, and telecommunication engineers because they are keen to ensure the radiations penetrate building environments for better operation of wireless electronic devices. Professionals from construction industry have overlooked this area, in particular the potential hazards posed by the radiations. The professional's role to design and construct buildings that shield occupants from the effects of the surrounding environment has fallen short of this consideration. This is an important area to the industry since electromagnetic radiations may not only affect human health but can interfere with occupants' normal equipment operation. It is the duty of building designers to ensure we live in a healthy environment yet perform our activities in a conducive internal environment.

\section{Acknowledgments}

We are indebted for a support from organizations and individuals who made this research possible. Thanks go to Eng. Thabit Jecha of Zantel for his directives and technical support in interpreting the electronic information. We will not forget Mr. Nassir Moh'd for his contribution in collecting field data and
Mr. Mohammed Abdullah (BEST) for the skillful proofreading. Special thanks go to SIDA (Swedish Development Agency) for their financial support to carry out the research. Lastly, to research and publication committee of Ardhi University for selecting this project for the award of the fund.

\section{References}

[1] Rifai, A. B., and Hakami, M. A. 2014. "Health Hazards of Electromagnetic Radiation." Journal of Biosciences \& Medicines 2 (8): 1-2.

[2] Pattazhy, S. 2012. "Electromagnetic Radiation (EMR) Clashes with Honeybees." Journal of Entomology \& Nematology 4 (1): 1-3.

[3] Lee, H. H., and Yen, T. 2010. "Upgrading on Cement-mortar Properties for Electromagnetic Wave Shielding in Buildings." In Proceedings of the $2^{\text {nd }}$ International Conference on Mechanical \& Electronic Engineering (ICMEE), Vol. 1, 1-3: p. 437-441.

[4] Al-Orainy, A. 2003. "Recent Research on Mobile Phones Effects." In Proceedings of the International Conference on Non Ionizing Radiation at UNITEN.

[5] WHO. 2011. "Electromagnetic Fields and Public Health: Mobile Phones." Fact Sheet No. 193. Accessed September 17, 2018. http://www.who.int/mediacentre/factsheets/ fs193/en/.

[6] Ogrutan, P. L., Aciu, L. E., and Stanca, C. 2014. "Attenuation Characteristics of Electromagnetic Shielding Material." Journal of Environmental Research and Protection 11 (1): 66.

[7] Lasiter, H. 1964. "Building Materials for Attenuating Electromagnetic Interference." Defense Technical Information Center, Accession Number AD 612149.

[8] Cho, S., Kim, J., and Hong, I. 2017. "Electromagnetic Shielding Characteristics of Foamed Concrete Wall." International Journal of Antennas \& Propagation (N.A): Article ID 9794053.

[9] Ahmadi-Shokouh, J., Noghanain, S., Hossain, E., Ostadrahimi, M., and Dietrich, J. 2009. "Reflection Coefficient Measurement for House Flooring Materials at 57-64 GHz." In Proceedings of the IEEE Global Telecommunications Conference (GLOBECOM'09), 1-6.

[10] Micheli, D. Delfini, A., Santoni, F., Volpini, F., and Marchetti, M. 2016. "Electromagnetic Shielding of Building Walls, from Roman Times to the Present Age." IEEE Antennas \& Propagation Magazine 58: 20-31.

[11] Brown, G. Z., and DeKay, M. 2001. Sun, Wind \& Light: Architectural Design Strategies (2nd ed.). New York: John Wiley \& Sons, Inc.

[12] Hemming, L. H. 1992. Architectural Electromagnetic 
Shielding Handbook: A Design and Specification Guide. Piscataway, NJ: IEEE Press.

[13] IEEE (The Institute of Electrical and Electronics Engineers). 1997. IEEE Standard Method of Measuring the Effectiveness of Electromagnetic Shielding Enclosures. IEEE Std. 299, IEEE Inc., New York, USA.

[14] Siravo, F. 1997. Zanzibar: A Plan for the Historic Stone Town. Zanzibar: The Gallery Publications. 